\title{
ROTA CRÍTICA: OS OBSTÁCULOS ENFRENTADOS PELA MULHER PARA SE DESVENCILHAR DA SITUAÇÃO DE VIOLÊNCIA INTRAFAMILIAR ${ }^{1}$
}

\author{
Jéssyca Yasmyn Fernandes Abreu Sales FMSJC ${ }^{2}$ \\ Jhonatan de Carvalho Bezerra FMSJC ${ }^{3}$ \\ Damaris do Nascimento Dias FMSJC ${ }^{4}$ \\ Ana Cecília Carvalho Sousa Morais Helal FMSJC ${ }^{5}$
}

\section{RESUMO}

O presente trabalho tem como objetivo geral investigar quais as dificuldades enfrentadas por mulheres que sofrem ou sofreram violência por companheiros ou membros da família. Como objetivos específicos: identificar dificuldades pra se desvencilhar do ciclo de violência, analisar a forma como as mulheres são amparadas após sofrerem esse tipo de violência e discutir sobre o papel da Coordenadoria Municipal de Defesa dos Direitos da Mulher-CODIM nos casos de violência intrafamiliar. Trata-se de uma pesquisa de campo de natureza qualitativa em que se utilizou como instrumento de coleta de dados a entrevista com um sujeito que é a coordenadora do CODIM amparada pela rota crítica e, ainda duas mulheres que foram vítimas de violência doméstica. A partir dos resultados das entrevistas constatou-se que, a maioria das mulheres enfrentam os mesmos pontos de dificuldades para buscar ajuda. E hoje elas necessitam de um centro de apoio.

Palavras-Chave: Violência intrafamiliar. Mulher. Rota crítica. Obstáculos. Enfrentamento.

\section{ABSTRACT}

The present work aims to investigate the difficulties faced by women who have suffered or suffered violence by partners or family members. Specific objectives are: to identify difficulties in disentangling themselves from the cycle of violence, to analyze the way women are supported after suffering this type of violence, and to discuss the role of the Municipal Coordination for the Defense of Women's Rights (CODIM) in cases of domestic violence. This is a qualitative field research that used as data collection instrument the interview with a subject who is the coordinator of CODIM supported by the critical route and also two women who were victims of domestic violence. From the results of the interviews it was found that most women face the same points of difficulty to seek help. And today they need a support center.

Key-words: Violence within the family. Woman. Critical route. Obstacles. Coping.

\footnotetext{
${ }^{1}$ Trabalho apresentado no Congresso Brasileiro Ciência e Sociedade (CBCS 2019), promovido pelo Centro Universitário Santo Agostinho, de 03 a 05 de outubro de 2019, em Teresina-PI.

${ }^{2}$ Graduanda do Curso de Direito da Faculdade Maranhense São José dos Cocais, yasmynsales@outlook.com

${ }^{3}$ Graduanda do Curso de Direito da Faculdade Maranhense São José dos Cocais, jhony_bezerra@yahoo.com.br

${ }^{4}$ Graduanda do Curso de Direito da Faculdade Maranhense São José dos Cocais, damarisdias045@gmail.com

${ }^{5}$ Orientadora mestranda na UFPI, anaceciliacsm25@hotmail.com
} 


\section{INTRODUÇÃO}

Tratar de violência intrafamiliar não é só falar de violência do seu companheiro ou namorado, mas também de membros da família ou de pessoas que convivem com aquela mulher agredida. As violências que as mulheres sofrem hoje são advindas de uma historia de patriarcalismo e machismo, perpassando ao longo dos séculos. Saffioti (2004) fala que:

Do mesmo modo como as relações patriarcais, suas hierarquias, sua estrutura de poder contaminam toda sociedade, o direito patriarcal perpassa não apenas a sociedade civil, mas, impregna também o Estado. (SAFFIOTI, 2004, p.54).

O presente trabalho tem como objetivo geral investigar quais as dificuldades enfrentadas por mulheres que sofrem ou sofreram violência intrafamiliar. Como objetivos específicos: identificar as dificuldades pra se desvencilhar do ciclo de violência, analisar a forma como as mulheres são amparadas após sofrerem esse tipo de violência e discutir sobre o papel da Coordenadoria Municipal de Defesa dos Direitos da Mulher-CODIM nos casos de violência intrafamiliar. Conhecer, principalmente, os gargalos e obstáculos no processo de rompimento da violência, se faz necessário e fundamental na aplicação de políticas públicas de enfrentamento e atendimento a violência mais eficazes. (EVANGELISTA, 2018, p.23)

Trata-se, portanto, de uma pesquisa de campo de natureza qualitativa em que se utilizou como instrumento de coleta de dados a entrevista com a coordenadora do CODIM amparada pela rota crítica e, ainda duas mulheres que foram vítimas de violência intrafamiliar, especialmente, na cidade de Timon.

\section{O QUE É ROTA CRÍTICA?}

O conceito de "Rota Crítica" começa com a decisão e determinação das mulheres de se apropriarem de suas vidas e dos seus filhos, levando-as a procurar ajuda (SAGOT, 2000, p.7). 


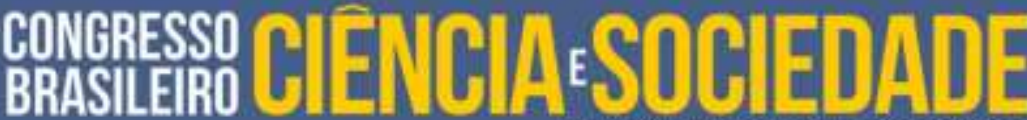

O caminho fragmentado que a mulher em situação de violência percorre buscando o atendimento do Estado. Essa lacuna que é deixada pelo Estado quando não tem um Centro especializado para acolher aquela mulher agredida seria preenchida pela "rota crítica", que consiste no acompanhamento e acolhimento dessas mulheres, por profissionais da saúde, assistência social e jurídica. Pois após ir à delegacia e fazer a denúncia, ela necessita de um acompanhamento direcionado para aquela situação em particular, pois são vários tipos de violência.

Dias (2015) afirma que:

Desde que o mundo é mundo humano, a mulher sempre foi discriminada, desprezada, humilhada, coisificada, objetivizada, monetarizada. Ainda assim, a violência de que as mulheres são vítimas no reduto doméstico, nunca mereceu a devida atenção, nem da sociedade, nem do legislador, e muito menos do Judiciário. A ideia sacralizada da família e a inviolabilidade do domicílio sempre serviram de justificativa para barrar qualquer tentativa de coibir o que acontecia entre quatro paredes. Como eram situações que ocorriam no interior do "lar, doce lar", ninguém interferia. (DIAS, 2015, p.31)

O que se percebe e que nesse ponto e que o "certo" seria outros não se envolverem em uma discussão doméstica, pois o casal tinha que resolver seus problemas sozinhos sem interferência de terceiros, mesmo que a mulher padecesse nessa relação. Isso fez com que algumas mulheres buscassem mudanças em sua vida. Essa mudança se iniciou na educação. Foi assim que começaram a ganhar dinheiro e sustentar a casa.

Mas, ao mesmo tempo em que ganhavam ascensão, aumentava a raiva e o machismo de alguns homens. E a forma de demonstração desse desconforto masculino é a violência psicológica, física e sexual. E em casos mais graves o feminicídio se utilizando de outros "pretextos" como ciúme, infidelidade, os de maiores índices. A questão, aqui, não são os "motivos" de violência contra a mulher, mas sim mostrar como a mulher é tratada na nossa sociedade mesmo após as agressões. Que a mulher é tratada com falta de respeito e com violência há séculos, já se sabe, mas a proporção desse fator é muito preocupante. 
No Brasil, a "rota crítica" não funciona como deveria, pois quando as mulheres chegam buscando atendimento, elas enfrentam muitas vezes violência institucional por parte de profissionais que pouco sensibilizados reproduzem discriminação contra as mulheres nos serviços de atendimento. Sagot (2000) fala que:

[...] as dificuldades encontradas na tomada de tal decisão suas percepções das respostas institucionais e as representações sociais e significados da violência intrafamiliar que existem entre o pessoal das instituições que devem oferecer respostas a essas questões. Este grave problema de saúde pública. Por fim, aprendemos sobre suas frustações que, em muitos casos, os levam de volta à situação de devoção. (SAGOT, 2000, p.7)

A mulher quando procura ajuda tem que ter uma "escuta ativa", que essa "escuta ativa" não é um acolhimento e sim uma forma solidária com aquela mulher, que ela se sinta bem e confortável em conversar com aquele profissional, pode ser face-a-face ou até mesmo por telefone. Soares (2005) afirma que:

Muitas vezes, uma mulher em situação de violência se sente especialmente amedrontada e envergonhada por não conseguir se fazer ouvir e respeitar por seu agressor. Quando pede ajuda, ela quer também ser escutada. A escuta do(a) profissional não pode, portanto, ser uma reação meramente passiva. Ao contrário, uma boa escuta é uma demonstração ativa de que a pessoa que fala está, de fato, sendo ouvida. (SOARES, 2005, p.47)

A iniciativa de programas sociais é bastante importante no combate e prevenção da violência contra a mulher. Mesmo com programas e iniciativas em todo mundo de combate a violência contra a mulher, ainda há muito a ser feito para acabar com a desigualdade e consequente violência de gênero. (DUDRA, 2015)

A Lei Maria da Penha veio para explicar os tipos de violência doméstica e o parentesco da relação de convívio doméstico pelas mulheres que sofrem violência, e Guimarães (2014) afirma que:

Na violência doméstica e familiar contra a mulher não é necessário que a agressão ocorra no ambiente doméstico, basta exigir o parentesco ou uma relação de convívio entre o agressor homem ou mulher, como nos casos de 


\section{conversso CIENCIASSOCIEDADE

namorados, ex-namorados, ex-maridos ou maridos, sendo a vítima sempre uma mulher. (GUIMARÃES, 2014, p.4)

A rede de apoio tem que se utilizar dos mecanismos que a Lei Maria da Penha nos mostra, como identificar os tipos de violência contra a mulher. De acordo com o artigo 70 da Lei Maria da Penha: Lei 11.340 de 07 de agosto de 2006, a violência familiar e doméstica pode ser refletida da seguinte forma:

I. Violência física: Entendida como qualquer conduta que ofenda sua integridade ou saúde corporal;

II. Violência psicológica: Entendido como conduta que the cause dano emocional e diminuição da autoestima ou que lhe prejudique e perturbe o pleno desenvolvimento ou que vise degradar ou controlar suas ações, comportamentos, crenças e decisões, mediante ameaça, constrangimento, humilhação, manipulação, isolamento, vigilância constante, perseguição, insulto, chantagem, ridicularizarão, exploração e limitação do direito de ir e vir ou qualquer outro meio que lhe cause prejuízo à saúde psicológica e à autodeterminação;

III. Violência sexual: Entendida como qualquer conduta que constranja a presenciar, a manter ou a participar de relação sexual não desejada, mediante intimidação, ameaça coação, ou uso da força; que a induza a comercializar ou a utilizar, de qualquer modo, a sua sexualidade, que a force ao matrimônio, a gravidez, ao aborto ou a prostituição, mediante coação, chantagem, suborno ou manipulação; ou que limite ou anule o exército de seus direitos sexuais e reprodutivos;

IV. Violência patrimonial: Entendida como qualquer conduta que configure retenção, subtração, destruição parcial ou total de seus objetos, instrumento de trabalho, documentos pessoais, bens valores e direitos ou recursos econômicos, incluindo os destinados a desfazer suas necessidades;

V. Violência moral: Entendida como qualquer conduta que configure calúnia, difamação ou injuria. (BRASIL, Lei 11.340, 2006, artigo 7으)

No Brasil, nos últimos 12 meses do ano de 2018, 1,6 milhão de mulheres foram espancadas ou sofreram tentativas de estrangulamento, $42 \%$ sofreram violência doméstica e 52\% não denunciou a agressão ou procurou ajuda. Esses são dados da pesquisa feita pelo Datafolha em fevereiro do ano 2019 encomendada pela ONG Fórum Brasileiro de Segurança Pública (FBSP). Para se construir um local de apoio para essas mulheres, é necessário um envolvimento não só do poder público mais da 


\section{congersSOCEIENCIASSOCIEDADE

sociedade como um todo. (DATAFOLHA, encomendada pela ONG - Fórum Brasileiro de Segurança Pública)

As mulheres maltratadas tendem a manifestar vários tipos de problemas, quando são deixadas vivas após a violência intrafamiliar, uma delas são as dores crônicas a baixa estima e a depressão seguida de suicídio. A pressão, a vergonha, a falta de apoio são tão grandes que as levam a tirar a própria vida. Como pesquisadores devemos ter um olhar de cuidado e de querer ajudar essas mulheres. (GARBIN, DOSSI, 2006)

As mulheres vindas de agressões de seus parceiros passam por momentos difíceis que as tornam frágeis e suscetíveis a pensamentos ruins e ações ruins. Por isso quando uma mulher procura ajuda é por que já está em seu limite. Nessa hora é onde a "rede de apoio" deve entrar e ouvir no primeiro momento essa mulher. Muito se fala em ouvir a mulher vinda de uma rotina de agressão, mas como deve-se ouvi-la? É uma pergunta muito importante. E que deve ser utilizada ao pé da letra. Os profissionais que terão o primeiro contato com essa mulher e muitos casos com seus filhos devem se humanizar antes de capacitar-se.

Essa humanização deve vir do querer do profissional do querer ajudar essa mulher. Por isso a importância do a ouvir e entender o que aquela mulher frágil, machucada, abusada e violentada quer que a "rede de apoio" faça por ela. Pois muitas das vezes a denúncia ou a medida protetiva não vai bastar. Ela provavelmente quer e precisa ser retirada daquela cidade que vive com seu agressor.

Por isso a necessidade de destinação de fundos para essas instituições de apoio a mulher que sofre agressão intrafamiliar, pois ela não irá só precisar de apoio dos profissionais, mas também de dinheiro para que se necessário sair daquele cidade, e tentar uma nova vida ao lado de seus filhos ou mesma sozinha, para as mulheres que são agredidas e não tem filhos.

ROTA CRÍTICA NA PERSPECTIVA DA COORDENADORA DO CODIM - TIMON: ANÁLISE E DISCUSSÃO 


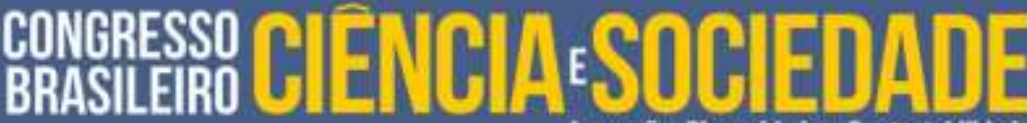

$\mathrm{Na}$ visita ao CODIM, uma profissional foi abordada e informou pontos importantes a serem destacados neste trabalho e nos ofereceu dados atuais do DEAM. Seu trabalho como coordenadora permitiu um leque de informações relevantes a esta pesquisa. Para tanto foi realizada uma entrevista com a profissional que passou as informações que seguem no texto.

A coordenadora informou que existem cinco pontos principais para que se torne difícil o desvencilhar da violência intrafamiliar das mulheres de Timon: I) o cultural, pois a sociedade e até mesmo as mulheres são preconceituosas por pensar em deixar o marido; elas mesmo se martiriza por ter que tomar uma atitude que ela vai sofrer preconceito, ter que "desmanchar" sua família; II) social, que a sociedade não as veem com bons olhos por ter deixado o marido o pedir o divórcio por conta de briga doméstica, o social abala muitos essas mulheres, pois além do preconceito que sofrem pelas "costas" escutam na "cara" que foram erradas em sair de casa por briga "besta"; III) o terceiro, elas se perguntam onde vão morar? Voltar para a casa dos pais? Muitas vezes elas não têm essa opção, pôr os pais terem preconceito ou vergonha da filha que agora está separa com filhos e voltando para a casa; IV) como vou viver? Muitos casos essas mulheres que vivem sob violência intrafamiliar são sustentadas pelo o agressor ou por outro parente, e quando têm filhos a situação fica pior, pois não é só elas que vão precisar de dinheiro para sobreviver, mas os filhos também; V) o mais grave de todos, o medo da morte, chega a um ponto que as ameaças ficam mais graves, com risco de feminicídio. Com esses pontos dificultam a procura por acolhimento dessas vítimas.

Conforme a coordenadora informou, em Timon, não há uma casa-abrigo, o que é essencial, após a denúncia. Há um Centro Pop, mas para o caso dessas mulheres, que na maioria tem crianças e estão ameaçadas não é de muita ajuda. O primeiro local que essas mulheres chegam com algum tipo de reclamação ou desconforto é na saúde, nos médicos de PSF, com queixas de dores nos genitais ou depressão, pois muitas são caladas ou se calam por medo dos médicos denunciarem o seu companheiro. Por isso a grande necessidade de uma casa-abrigo para elas. Pois lá terão uma rede de apoio para que possam tratar de seus problemas físicos e mentais. 


\section{conph SESOCENCIASSOCIEDADE

A rede de apoio que Timon oferece hoje é o CODIM, Delegacia, Juizado, Defensoria Pública, Promotoria, CREAS, Saúde, Educação/Social, PM e a Guarda Municipal. É assim que essas mulheres são assistidas em Timon, o problema é que depois de tudo isso elas não têm o acompanhamento necessário, em Timon, dados atuais do DEAM de 2018 mostram que existem 515 mulheres com medidas protetivas, e nenhuma delas foi acompanhada acolhida após a medida protetiva. Isso as torna vulneráveis perante seus agressores. A coordenadora expôs, ainda que a mídia é um veículo de desconstrução da Lei Maria da Penha. A mídia afirma que a lei não funciona, critica a lei, sendo que ela não pode agir sozinha, é aí que entra a rede de apoio junto ao judiciário e o social.

\section{EXPERIÊNCIA DE MULHERES AGREDIDAS}

Para melhor ilustrar esta pesquisa, foram abordadas também mulheres que relataram os tipos de violência que sofreram e a dificuldade enfrentada por elas. Para manter o sigilo das entrevistadas usaram-se nomes fictícios.

Carla, 35 anos, três filhos, ensino superior completo, nos falou que a dificuldade que ela teve de denunciar foram os filhos, em especial, o filho mais velho que pedia pra ela não denunciar o pai. E assim ela o fez, pois além do pedido do filho ela também precisava da sogra para ajudar a cuidar dos três filhos. Mas isso logo mudou, pois de agressões psicológicas passaram a ser física, e com a ajuda de certa forma da sogra. Ela chegou ao ponto de esconder-se na casa de sua mãe, para que o marido "acalmasse", pois falava em matá-la, alegando traição. Ela relatou que foi difícil, mas fez a denúncia, e, após ter feito, mudou-se para a casa dos pais sem os filhos, em casa ela não recebeu muito apoio, pois eles queriam que ela tentasse mais uma vez o casamento ou pelo menos tivesse os filhos de volta, porém, ela alegava que não poderia ir buscá-los, pois o ex-marido a ameaçava de morte.

Ela relatou ainda que dentre as maiores dificuldades estavam, deixar os filhos na casa da sogra, além da falta de apoio de um órgão que a amparasse, na cidade. Hoje ela tem uma medida protetiva contra seu ex-marido, que na ocasião da audiência falou que não queria "matar" só "feri-la". A convivência ou conversa entre eles hoje não 


\section{congesESOCEIENCIASSOCIEDADE

existe mais, mesmo depois de dois anos do ocorrido. E como as crianças são menores ela inda está em processo de divórcio e lutando por pensão pra os filhos.

Além de Carla, outra mulher foi abordada. Dani, 36 anos, três filhos, ensino superior completo, sofria de violência verbal do marido, na maioria das vezes quando ele chegava bêbado, as brigas eram originadas pela desconfiança por parte do companheiro. Conforme seus relatos, a família sabia de algumas brigas deles, mas o que dificultava Dani de sair de casa era o fato de não trabalhar e não ter para onde ir com os três filhos.

Quando Dani conseguiu separar-se dele arrumou trabalho, fez a inscrição no programa minha casa minha vida, conseguiu pagar uma faculdade. No primeiro momento ela ficou na casa da mãe com os três filhos, após receber a casa do programa, mudou-se para lá com os dois filhos mais velhos, a mais nova ficou na casa da avó materna, pois a casa dela era mais próxima da escola, já que os dois filhos mais velhos tinham terminado o ensino médio. Hoje, apenas a filha mais nova tem contato com o pai, os dois mais velhos não querem muito contato com o pai. Dane e seu excompanheiro não são separados judicialmente, hoje ela já namora outra pessoa.

\section{CONSIDERAÇÕES FINAIS}

O que se constata é que o primeiro passo que elas dão, sempre será a coragem de denunciar o companheiro ou namorado na delegacia da mulher, para algumas pessoas pode ser simples, mas para essas mulheres é difícil e requer uma coragem que nem elas sabem explicar, mas acredito que seja a vontade de viver que as impulsionem a buscar ajuda. Diferente da capital Teresina, o índice de feminicídio foi zero no ano de 2018 em Timon mesmo próximo a cidade de Teresina. E as medidas protetivas têm sido muito importantes para as mulheres timonenses. E o trabalho de divulgação da CODIM, é fundamental na cidade para que as mulheres busquem ajuda e conheçam seus direitos. E principalmente para que vejam que não estão sozinhas nessa batalha. $E$ ainda é complicado à questão de partilhar experiências, pois ainda é um tabu para muitas delas falarem abertamente sobre violência intrafamiliar com outras pessoas. 
As entrevistas foram bem maleáveis, para que elas se sentissem em uma conversa, por isso optou-se por uma entrevista. Elas foram bem receptivas quanto a responder as perguntas. E só o fato de poder servir como um meio de ajuda para outras mulheres, foi bastante significativo para elas.

Conclui-se, portanto, que o preconceito sempre vai existir e machismo, mas o que podemos mudar e a visão das crianças de hoje que se tornem adultos atuantes na mudança dessa nossa atual realidade. Sempre a educação básica vai ser uma arma contra a violência da mulher. Pois é da base que formamos cidadãos conscientes e mais receptível com a igualdade das mulheres.

Timon necessita de um grupo de apoio para acompanhar essas mulheres que fizeram denúncia que estão com medidas protetivas, as que só querem conversar, pois elas precisam sentir que são acolhidas, ouvidas e protegidas de seus agressores. Timon necessita de um local estruturado com profissionais da saúde para conversar, encontros de no mínimo mensais ou quinzenais, e uma casa-abrigo. Toda uma estrutura voltada para essas mulheres vindas de situação de violência e algumas correndo risco de vida.

\section{REFERÊNCIAS}

BRASIL. Lei Maria da Penha: Lei 11.340 de 07 de agosto de 2006.

DIAS, Maria Berenice. Lei Maria da Penha: a efetividade da Lei 11.340/2006 de combate à violência doméstica e familiar contra a mulher. 4.ed. Fev - atual e ampl. São Paulo: Editora Revista dos Tribunais. 2015.

DUTRA, Paula Queiroz. 0 paraíso não é aqui: à violência contra a mulher em Tatiana Salem Levy. 2015. Disponível em:

https://dialnet.unirioja.es/descarga/articulo/5506051.pdf. Acessado em: 22 de maio de 2019.

Estatísticas DEAM - 2018.

EVANGELISTA, lanara Silva. "cê vai se arrepender de levantar a mão pra mim": rotas críticas de mulheres que romperam o ciclo de violência. Disponível em: https://repositorio.ufpi.br/xmlui/handle/123456789/1821. Acessado em 09 de outubro de 2019. 


\section{conpGESSOCOENCASSOCIEDADE \\ Inovaço, fivercilails e Sustentalifilade}

GARBIN, C., GARBIN, A., DOSSI, A., DOSSI, M. Violência doméstica: análise das lesões em mulheres. 2006. Disponível em: https://www.scielosp.org/scielo.php?pid=S0102311X2006001200007\&script=sci_arttext\&tIng=en. Acessado em 21 de maio de 2019.

GUIMARÃES, Maria do Socorro Miranda. Violência contra a mulher no âmbito doméstico e família e a Lei Maria da Penha: uma revisão bibliográfica. 2014. Disponível em: https://repositorio.ucb.br/.../Maria\%20do\%20Socorro\%20Miranda\%20Guimarães.pdf Acessado em 24 de maio de 2019.

La ruta crítica de las mujeres afectadas por la violência intrafamiliar em América Latina: estudios de caso de diez países. San José: Oraganización Panamericana de la Salud (OPAS) / Programa Mujer, Salud y Desarrollo, 2000.

SOARES, Bárbara M. Enfrentando a violência contra a mulher: Orientações práticas para profissionais e voluntários(as). Brasília: Secretaria Especial de Políticas para Mulheres/CESeC; Presidência da República: Brasília, p. 47, 2005. Disponível em: https://www.ucamcesec.com.br/wpcontent//uploads/2011/06/manual_enfretando_violencia1.pdf. Acessado em 23 de maio de 2019.

SAFFIOTI, Heleieth I. B. Gênero, patriarcado, violência. São Paulo: Fundação Perseu Abramo, 2004. (Coleção Brasil Urgente) 